\title{
What is the impact of systems of care for heart failure on patients diagnosed with heart failure: a systematic review
}

Andrea Driscoll ${ }^{1 *}$, Sharon Meagher ${ }^{1}$, Rhoda Kennedy ${ }^{1}$, Melanie Hay ${ }^{2}$, Jayant Banerji ${ }^{3}$, Donald Campbell ${ }^{4}$, Nicholas Cox ${ }^{5}$, Debra Gascard ${ }^{6}$, David Hare ${ }^{7}$, Karen Page ${ }^{1}$, Voltaire Nadurata ${ }^{8}$, Rhonda Sanders ${ }^{9}$ and Harry Patsamanis ${ }^{2}$

\begin{abstract}
Background: Hospital admissions for heart failure are predicted to rise substantially over the next decade placing increasing pressure on the health care system. There is an urgent need to redesign systems of care for heart failure to improve evidence-based practice and create seamless transitions through the continuum of care. The aim of the review was to examine systems of care for heart failure that reduce hospital readmissions and/or mortality.

Method: Electronic databases searched were: Ovid MEDLINE, EMBASE, CINAHL, grey literature, reviewed bibliographies and Cochrane Central Register of Controlled Trials for randomised controlled trials, non-randomised trials and cohort studies from $1^{\text {st }}$ January 2008 to $4^{\text {th }}$ August 2015. Inclusion criteria for studies were: English language, randomised controlled trials, non-randomised trials and cohort studies of systems of care for patients diagnosed with heart failure and aimed at reducing hospital readmissions and/or mortality.

Three reviewer authors independently assessed articles for eligibility based on title and abstract and then full-text. Quality of evidence was assessed using Newcastle-Ottawa Scale for non-randomised trials and GRADE rating tool for randomised controlled trials.

Results: We included 29 articles reporting on systems of care in the workforce, primary care, in-hospital, transitional care, outpatients and telemonitoring. Several studies found that access to a specialist heart failure team/service reduced hospital readmissions and mortality. In primary care, a collaborative model of care where the primary physician shared the care with a cardiologist, improved patient outcomes compared to a primary physician only. During hospitalisation, quality improvement programs improved the quality of inpatient care resulting in reduced hospital readmissions and mortality. In the transitional care phase, heart failure programs, nurse-led clinics, and early outpatient follow-up reduced hospital readmissions. There was a lack of evidence as to the efficacy of telemonitoring with many studies finding conflicting evidence.
\end{abstract}

Conclusion: Redesigning systems of care aimed at improving the translation of evidence into clinical practice and transitional care can potentially improve patient outcomes in a cohort of patients known for high readmission rates and mortality.

Keywords: Heart failure, Systems of care, Hospital readmissions, Primary care, Hospitalisations, Transitional care, Workforce, Systematic review

\footnotetext{
* Correspondence: andrea.driscoll@deakin.edu.au

'Deakin University, Locked Bag 20000, Geelong, VIC 3220, Australia

Full list of author information is available at the end of the article
} 


\section{Background}

Approximately 1-3 \% of the adult population have been diagnosed with heart and one in five people will develop heart failure during their lifetime with the incidence increasing with age [1]. The prognosis of heart failure is poor with a $10 \%$ in-hospital mortality rate from acute heart failure, post-discharge $20-40 \%$ mortality rate within one year, and 20-25\% will be readmitted within one month [2-7]. Over the natural course of heart failure, people will experience acute episodes requiring urgent medical treatment and hospitalisation. Hospital admissions for heart failure are predicted to rise substantially over the next decade placing increasing pressure on the health care system as health care costs associated with heart failure will also dramatically rise. There is an urgent need to redesign health systems of care for heart failure to improve evidence-based practice and create seamless systems of care across the health care continuum embracing primary care, hospital and community care. This literature review will systematically review articles that focus on systems of care for heart failure aimed at reducing hospital readmission and mortality rates. A system of care is defined as one or several interventions implemented for service delivery in health care.

\section{Methods}

\section{Types of studies}

Studies included in the review implemented an intervention or interventions involving health service delivery aimed at reducing hospital readmissions and mortality for patients diagnosed with heart failure. Patients diagnosed with heart failure with reduced (HFrEF) and/or preserved ejection fraction (HFpEF) were included. All of the studies included in the review had received ethics approval.

\section{Search methods}

The search strategy was based on the PRISMA statement [8]. The following databases were searched for studies of systems of care for heart failure:

1. The Cochrane Central Register of Controlled Trials (CENTRAL, issue 7 of 12, searched 4/8/2015, results: 9)

2. MEDLINE (EBSCO host, 2008 to August week 1 2015, searched 4/8/2015, results: 145$)$

3. EMBASE (EMBASE platform, 2008 to 2015 week 31, searched 4/8/2015, results: 107$)$

4. CINAHL (EBSCO host, 2008 to August week 1 2015, searched 4/8/2015, results: 21 )

The Cochrane Highly Sensitive Search Strategy was used for MEDLINE and an adaptation of it for EMBASE and CINHL [9]. See Appendix 1 for details of the search strategies. We restricted the search to studies reported in English and from $1^{\text {st }}$ January 2008 to $4^{\text {th }}$ August 2015. There was no restriction on study design. We included randomised controlled trials, non-randomised trails and observational studies. All citations were imported into EndNote XVII ${ }^{\mathrm{TM}}$ electronic database.

The following clinical trials registries were also searched: WHO International Clinical Trial Registry Platform (ICTRP) (www.who.int/trialsearch) and clinical trials (www.clinicaltrial.gov ) (searched $5^{\text {th }}$ August 2015). Full reference lists of key eligible papers and review articles were searched to identify potential papers. We also searched the grey literature to identify unpublished theses, policy documents and abstracts. Reference lists of heart failure guidelines (national and international) and other systematic reviews and meta-analyses were also searched.

\section{Selection of studies}

All titles and abstracts were assessed for eligibility by three authors working independently. If the title and abstract contained sufficient information to determine exclusion, it was rejected. Where the type of intervention or study population was not clear from the title or abstract the full text of the paper was retrieved and evaluated to determine inclusion or exclusion. The reference lists of eligible papers were reviewed to identify potential papers. The principle reason for exclusion of papers and abstracts was documented based on inclusion criteria. Disagreements between the reviewers were resolved by discussion and consensus between the three authors.

\section{Assessment of quality of evidence for non-randomised con- trolled trials}

The Newcastle-Ottawa Scale (NOS) was used to assess the quality of non-randomised studies [10] (Table 1). This tool has been used previously in Cochrane Reviews for assessment of risk of bias in non-randomised studies with high inter-rater reliability and content validity [10]. The NOS comprises of eight items: representativeness of cohort, selection of cohort, ascertainment of exposure, outcome of interest was not present at baseline, comparability of cohorts, assessment of outcome, length of follow-up and adequacy of follow-up. When the paper under review met the criterion in the NOS, it was awarded $\mathrm{a}^{\text {(*)' }}$. A paper was also awarded an additional "*' if the analysis was adjusted for potential confounding variables. The quality of each study was graded as low, medium or high according to the number of stars $(*)$.

\section{Assessment of risk of bias for randomised controlled trials}

The Cochrane Collaboration tool for risk assessment [11] was used. Each randomised controlled trial was assessed for selection bias, performance bias, attrition bias, and detection bias (Table 2). The risk of bias was assessed as low, high or unclear. Study quality was not a reason for exclusion of a study. 
Table 1 Summary of Quality Assessment (Newcastle-Ottawa Scale): Non randomised studies

\begin{tabular}{|c|c|c|c|c|c|c|c|c|c|}
\hline \multirow[t]{2}{*}{ Study } & \multicolumn{4}{|l|}{ Selection } & \multirow{2}{*}{ 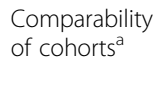 } & \multicolumn{3}{|l|}{ Outcome } & \multirow{2}{*}{$\begin{array}{l}\text { Evidence } \\
\text { quality }^{b}\end{array}$} \\
\hline & $\begin{array}{l}\text { Exposed cohort } \\
\text { representative }\end{array}$ & $\begin{array}{l}\text { Non exposed } \\
\text { cohort selection }\end{array}$ & $\begin{array}{l}\text { Exposure } \\
\text { ascertainment }\end{array}$ & $\begin{array}{l}\text { Outcome not } \\
\text { present at start }\end{array}$ & & Assessment & $\begin{array}{l}\text { Follow-up } \\
\text { length }\end{array}$ & $\begin{array}{l}\text { Follow up } \\
\text { adequacy }\end{array}$ & \\
\hline \multicolumn{10}{|l|}{ Workforce } \\
\hline Zuily, 2010 [15] & * & * & $*$ & * & $* *$ & * & * & * & High \\
\hline Boom, 2012 [13] & * & * & * & * & $* *$ & * & * & * & High \\
\hline NICOR, 2012 [12] & * & * & * & * & $* *$ & * & * & * & High \\
\hline Comin-Colet, 2014 [16] & * & * & * & * & $* *$ & $*$ & - & - & High \\
\hline \multicolumn{10}{|l|}{ Primary care } \\
\hline Lee, 2010 [18] & * & * & * & * & $* *$ & * & * & * & High \\
\hline Rosstad, 2013 [17] & * & * & * & * & - & - & - & - & Low \\
\hline \multicolumn{10}{|l|}{ In-hospital studies } \\
\hline Williams, 2010 [21] & * & * & * & * & - & * & * & $*$ & Low \\
\hline Tuso, 2014 [22] & * & $*$ & $*$ & * & - & $*$ & * & * & Low \\
\hline \multicolumn{10}{|c|}{ In-hospital clinical audits/registries/quality improvement initiatives } \\
\hline Boutwell, 2011 [33] & * & * & * & * & - & NA & NA & NA & Low \\
\hline Heidenreich 2012 [26] & * & * & * & * & $* *$ & * & * & * & High \\
\hline Hansen, 2013 [32] & * & * & * & * & * & * & * & * & Moderate \\
\hline $\begin{array}{l}\text { H2H National Quality } \\
\text { Improvement Initiative, } \\
2015 \text { (H2H program) [34] }\end{array}$ & * & * & * & * & - & NA & NA & NA & Low \\
\hline \multicolumn{10}{|l|}{ Transitional care } \\
\hline Driscoll, 2011 [45] & * & * & * & * & $* *$ & * & * & * & High \\
\hline \multicolumn{10}{|l|}{ Outpatient clinics } \\
\hline Fonarow, 2011 [51] & * & * & * & * & $* *$ & * & * & * & High \\
\hline Hernandez, 2010 [49] & * & * & $*$ & * & $* *$ & * & * & * & High \\
\hline Fenner, 2014 [50] & * & * & * & * & - & - & * & * & Low \\
\hline \multicolumn{10}{|l|}{ Telemonitoring programs } \\
\hline Piette, 2008 [60] & * & * & * & * & - & - & * & $*$ & Low \\
\hline Baker, 2013 [61] & * & * & * & * & $* *$ & * & * & * & High \\
\hline
\end{tabular}

NA not applicable as outcome data has not been reported at the time of the literature search

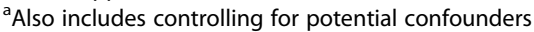

${ }^{\mathrm{b}}$ Evidence quality

Low: downgrading from moderate to low based on design or lack of information in report

Moderate: study met selection criteria (4 stars), comparability (1 star and upgraded a level for 2 stars), and outcome assessment

High: upgrading from moderate to high based on comparability of 2 stars

\section{Data synthesis}

Due to the diversity associated with the design and outcome measures in observational and cohort studies, meta-analysis for pooled estimates was not conducted so the data was synthesised qualitatively and consisted of a narrative synthesis of the evidence.

\section{Results}

A total of 520 studies were identified from the literature search. After removing the duplicate articles we reviewed the titles and abstracts of 487 articles. Of these abstracts, 212 full-text articles were identified for retrieval and possible inclusion in the literature review.
From the full-text articles we excluded 183 studies. We included 29 studies in the integrated literature review.

The PRISMA flow diagram in Fig. 1 outlines the selection process of studies included in the literature review. The studies were classified into four main categories, based primarily on the environment of delivery, relating to systems of care for heart failure: workforce, primary care, in-hospital and transitional/community systems of care. Workforce was included as a category as often the intervention spanned across multiple environments such as primary care, in-hospital and community. Appendix 2 provides a summary of the included studies. Systematic reviews, meta-analyses and policy documents have been excluded from Appendix 2. 
Table 2 Risk of bias: Randomised controlled trials

\begin{tabular}{|c|c|c|c|c|c|c|c|c|}
\hline Author, year & $\begin{array}{l}\text { Random sequence } \\
\text { generation }\end{array}$ & $\begin{array}{l}\text { Allocation } \\
\text { concealment }\end{array}$ & $\begin{array}{l}\text { Blinding of participants } \\
\text { and personnel }\end{array}$ & $\begin{array}{l}\text { Blinding of outcome } \\
\text { assessment }\end{array}$ & $\begin{array}{l}\text { Incomplete } \\
\text { outcome data }\end{array}$ & $\begin{array}{l}\text { Selective } \\
\text { reporting }\end{array}$ & $\begin{array}{l}\text { Other } \\
\text { bias }\end{array}$ & $\begin{array}{l}\text { Overall risk } \\
\text { of bias }\end{array}$ \\
\hline \multicolumn{9}{|l|}{ Transitional care7 } \\
\hline Jaarsma, 2008 [44] & Low & Unclear & High & Low & Low & Low & None & Low \\
\hline \multicolumn{9}{|l|}{ Nurse-led outpatient clinic } \\
\hline Driscoll, 2014 [45] & Low & Unclear & High & Unclear & Low & Low & None & Low \\
\hline \multicolumn{9}{|l|}{ Telemonitoring programs } \\
\hline Schwarz, 2008 [59] & Unclear & Low & High & Unclear & Unclear & Low & None & Unclear \\
\hline Woodend, 2008 [57] & Unclear & Low & High & Unclear & Low & Low & None & Low \\
\hline Chaudhry, 2010 [55] & Low & Unclear & High & Low & Unclear & Low & None & Low \\
\hline Koehler, 2011 [52] & Low & Unclear & High & Low & Low & Low & None & Low \\
\hline Angermann, 2012 [39] & Low & Low & High & Low & Low & Low & None & Low \\
\hline Dendale, 2012 [54] & Low & Low & High & Low & Low & Low & None & Low \\
\hline Pekmezaris, 2012 [56] & Low & Unclear & High & Unclear & Low & Low & None & Low \\
\hline Krum, 2013 [53] & Low & Low & Low & Low & Low & Low & None & Low \\
\hline Black, 2014 [58] & Low & Low & Low & Unclear & Unclear & Unclear & None & Unclear \\
\hline
\end{tabular}

\section{Specialist workforce}

When redesigning systems of care, an experienced workforce is critical to its success. Three studies examined the impact of workforce on patient outcomes. All of these studies were rated as a high quality of evidence (Table 2). Specialist heart failure teams within the community and in-hospital were associated with improved patient outcomes. A UK national heart failure audit, conducted between April 2010 to March 2011, found inpatient mortality rates were better in patients admitted under Cardiology (8\%) compared to General Medicine (14\%) and other wards (17\%) [12]. In another study, these benefits were also extended to lower 30-day and 12 month mortality rates [13]. Boom and colleagues [13] recruited 7634 patients newly hospitalised with heart failure. Patients who were admitted under a generalist physician and had a cardiologist involved in their care were more likely to undergo cardiac investigations during their inpatient stay. Patients treated by a generalist physician only were also at increased risk of 30-day mortality (odds ratio [OR] 1.50, $95 \%$ confidence interval [CI] 1.18-1.91) compared to patients that were admitted under a generalist physician and had a cardiologist involved in their care [13].

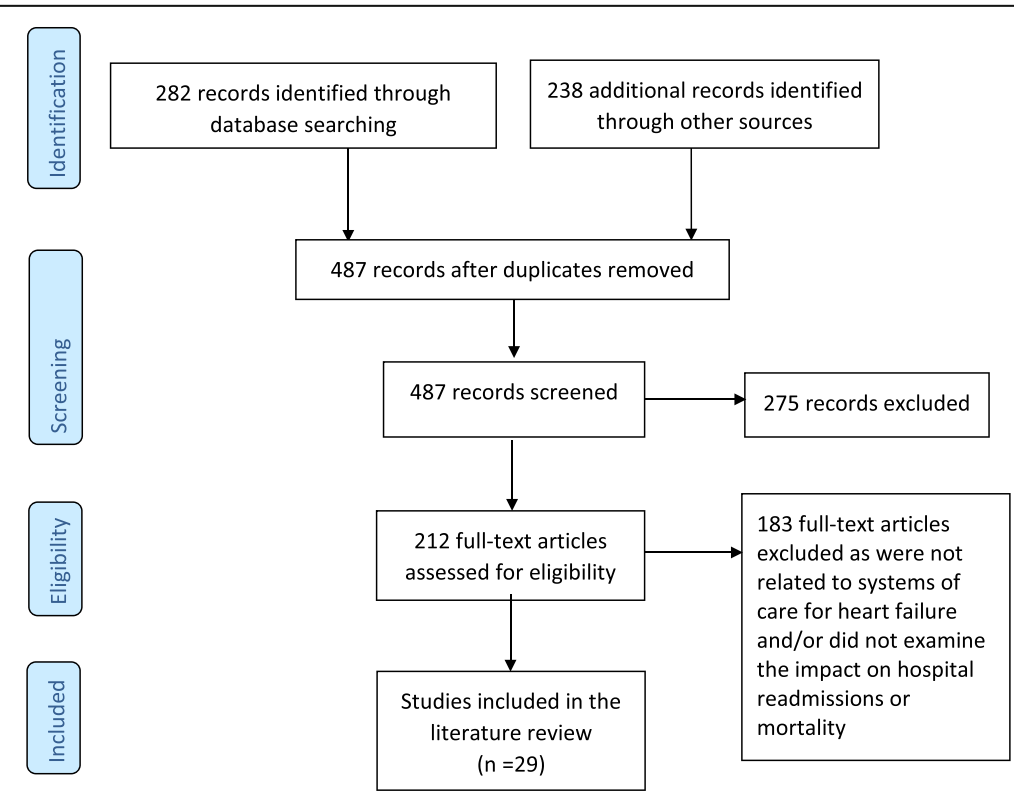

Fig. 1 Study flow diagram 
Improved outcomes were also seen in outpatient settings with lower mortality rates for patients followed up with cardiology clinics (18 \%) compared to noncardiology clinics (31 \%) [12]. There was also a similar trend with patients followed up with heart failure specialist nursing services (22\% mortality rate) compared to follow up with a non-heart failure specialist nurse (27 \%) [12]. A dedicated in-hospital heart failure unit also showed further reduction in heart failure readmissions and all-cause event-free survival $[14,15]$.

Comin-Colet and colleagues [16] implemented a health service-wide heart failure program encompassing an inpatient service, community service and a heart failure unit including a multidisciplinary specialist heart failure team. They examined hospital readmissions and mortality rates of 2083 patients, admitted with acute decompensated heart failure, to the hospital with a heart failure service compared to the outcomes associated with 54659 patients admitted, with acute decompensated heart failure, to hospitals with no heart failure service within the surrounding region. They found that patients admitted to the hospital with the heart failure service had a lower risk of death (hazard ratio [HR] 0.92, $95 \%$ CI 0.86-0.97), 29 \% less likely to experience a readmission for any cause (HR 0.71, 95 \% CI 0.66-0.76), and $14 \%$ lower risk of heart failure readmissions (HR 0.86, 95 \% CI 0.80-0.94) [16].

\section{Primary care}

Most of the literature examining systems of care for heart failure in primary care focused on a collaborative model of care and adherence to clinical guidelines. Of the two studies included, one was rated as a low [17] quality of evidence and the other as high [18] (Table 1). Lee et al. [18] examined readmission rates of 10599 heart failure patients discharged from emergency department (ED) who were managed in a collaborative care model comprising of a cardiologist and general practitioner compared to general practitioner only or no follow-up. Collaborative care (cardiologist and general practitioner) reduced mortality compared with general practitioner only (HR 0.79; $95 \%$ CI 0.63 to 1.00) [18].

Care pathways have also been trialed in primary care. Roostad [17] found that a disease-based care pathway was ineffective and unsustainable in primary care. This was mainly due to multiple co-morbidities that can be associated with heart failure and the need for multiple care pathways for each co-morbidity which may be contradictory to other care pathways. This study was rated as low quality of evidence as there was no follow up.

\section{In-hospital care}

Many studies implemented interventions to improve the translation of clinical practice guidelines into standard patient care with the aim of reducing 30 day readmissions. Hansen [19] undertook a systematic review of interventions implemented pre and post discharge to reduce 30-day readmissions. Pre-discharge interventions included: patient education, medication reconciliation, discharge planning, and scheduling of a follow-up appointment before discharge. Post-discharge interventions comprised of: follow-up telephone calls, patient activated hotlines, timely communication with ambulatory providers, timely ambulatory provider follow-up, and post-discharge home visits. Bridging interventions included transition coaches, physician continuity across the inpatient and outpatient setting, and patient centered discharge instruction. Hansen [18] found that no single intervention alone was associated with reduced risk for 30-day readmissions rather bundles of interventions were more effective. Care pathways were also associated with improved patient outcomes.

In the acute hospital setting, a meta-analysis of care pathways reported reductions in readmission (RR 0.81, $95 \% \mathrm{CI}$ 0.66-0.99) and in-hospital death rates (RR 0.45, $95 \% \mathrm{CI}$ 0.21-0.94) compared with usual care in patients hospitalized with acute heart failure [20]. However, the meta-analysis combined results from three randomised controlled trials, one interrupted- time series and three controlled trials so differences in patient characteristics may have affected the outcomes [20]. A limitation of care pathways is that one standardised care pathway will not be suitable for all hospitals so effectiveness varies greatly and the results of the meta-analysis should be interpreted with caution. Care pathways were also not found to be effective or sustainable in primary care [17].

In addition to a systematic review and meta-analysis, two studies implemented a system of care during the inpatient phase. Williams [21] implemented a quasi-experimental study to determine the effectiveness of an inpatient education program and discharge planning on reducing hospital readmission. All patients were followed up for 18 weeks post-discharge. They found no difference between groups for 30 day hospital readmissions. There was a significantly shorter length of hospital stay for patients in the education program compared to no education (10.68 days versus 9.58 days, $p=0.05$ ) [21]. The study had a low quality of evidence due to lack of controlling for confounding variables (Table 1).

One study implemented a 'heart failure bundle' [22]. This study was rated as a low quality of evidence mainly due to a lack of controlling for confounding variables during data analysis (Table 2). The bundle included: inpatient heart failure education, a home visit within $48 \mathrm{~h}$ of discharge, and a follow-up appointment and followup phone call from a heart failure care manager both within seven days of discharge. Readmissions rates were reduced from 19 to $15 \%$ over 30 -days $(p=0.03)$ [22]. 
In-hospital quality of care performance initiatives

Several studies discussed the implementation of large quality improvement programs and clinical inpatient registries to improve hospital management of heart failure patients. Considerable variation in the management of heart failure between hospitals exists [12, 21, 23]. Several studies showed an improvement in survival and reduction in readmission rates as patients with heart failure were cared for in hospitals that complied with clinical practice guidelines compared with hospitals with low compliance rates [23-26].

\section{Clinical audits/registries}

There are several national registries throughout the world: HEARTS in Saudi Arabia, CHART-2 in Japan, GULF CARE in Middle East, and ASIAN-HEART FAILURE in Asia [27]. Results from these registries are yet to be published. The implementation of many large clinical registries and clinical audits occurred prior to the time period of this literature search such as OPTIMISE [24], and ADHERE [23] and EuroHeart failure survey I [28] and II [2]. However, one large clinical audit was the UK national audit [12]. This study was assessed as a high quality of evidence rating (Table 2).

UK national heart failure audit In England and Wales, over the past four years, an annual national audit of patients admitted to hospital with acute decompensated heart failure has been undertaken. The latest national audit conducted between April 2010 and March 2011 collected data on 36 items (based on national guidelines) from 133 National Health Service Trusts and Welsh Health Boards on 36504 patients representing $54 \%$ of all hospital admissions for acute decompensated heart failure [12]. The audit found a large degree of heterogeneity in the management of heart failure across hospitals particularly the proportions of patients undergoing key diagnostic tests, receiving cardiovascular medications on discharge and being referred to cardiology follow-up services [12]. In-hospital mortality was lower for those patients admitted under Cardiology (8\%) compared to those patients admitted under General Medicine (14\%) and other Units $(17 \%)$. This trend also extended to post-discharge with an $18 \%$ mortality rate with Cardiology follow-up compared to $31 \%$ with non-cardiology follow up [12]. A similar trend was seen with patients followed by a specialist heart failure nurse at $22 \%$ mortality compared to $27 \%$ with no follow up with a heart failure specialist nurse. Unfortunately, hospital readmissions were not collected in the audit [12].

\section{Quality improvement initiatives}

Several nationwide quality improvement initiatives have also been implemented with the aim of reducing 30-day hospital readmissions. These include: Get with the Guidelines (GWTG)-HEART FAILURE, Better Outcomes for Older adults through safe transitions (BOOST) project, State Action on Avoidable Rehospitalisations (STAAR) program, and Hospital-to-Home program $(\mathrm{H} 2 \mathrm{H})$.

GWTG-heart failure The GWTG program was implemented by American Heart Association to address the gap in implementation of evidenced-based clinical practice guidelines with the aim of improving patient outcomes post discharge. Several disease-specific GWTG programs have been implemented: GWTG-Atrial Fibrillation, GWTG-Resuscitation, and GWTG-stroke. Registered hospitals receive access to GWTG toolkit specific for heart failure. The toolkit comprises of: initiation of evidence-based medications, implantation of appropriate device therapies, discharge education about heart failure, evaluation of left ventricular function, and post discharge follow-up appointment [29]. Data is then entered into a web based system and each participating hospital receives site level patient data to identify those at risk of readmission. The program also provides professional education, patient education resources, and clinical support tools. GWTG currently has data from over 5 million patients and over 2093 US hospitals that participated at least once in GWTG (http://www.heart.org/ HEARTORG/HealthcareResearch/GetWithTheGuideline sHEART FAILUREStroke/GetWithTheGuidelinesHeartF ailureHomePage/Get-With-The-Guidelines-Heart-Failur e-Home-Page_UCM_306087_SubHomePage.jsp) [29]. Results have shown an improvement in adherence to performance measures and systems of care but subsequent impact on patient outcomes has been disappointing [26, 30, 31]. Readmissions at 30-days was $24.5 \%$ and mortality at 30 days was $11 \%$ [26]. Readmission rates [26] and mortality [31] were significantly lower in hospitals participating in GWTG- heart failure. This study [26] had a high quality of evidence (Table 1).

BOOST project (Better Outcomes for Older adults through safe transitions) [32]. This was a quality improvement project to reduce hospital readmissions and length of stay for patients hospitalised with heart failure. Thirty hospitals enrolled in the project but only eleven submitted their data. In 2014, 180 hospitals were involved in the project [32]. The BOOST intervention consisted of a toolkit which contained: an implementation guide, project management tools, such as the Teach Back Training Curriculum, and PICO guidelines to evaluate the intervention. Sites were also provided with face-to-face training and 12 months of expert mentoring and coaching, and assistance to build a culture that supports organisational change to reduce hospital readmissions, also linking with other participating sites and data 
management. Each site also received project benchmark data and site level patient data. The average rate of 30day rehospitalisation was $15 \%$ pre-implementation and $13 \% 12$ months post-implementation [32]. There was no difference in length of stay. Unfortunately, not all of the hospitals implemented all of the quality tools, with the majority implementing two of the five BOOST tools. This study was rated as a moderate quality of evidence due to not adjusting for confounding variables (Table 1).

\section{STAAR program}

State Action on Avoidable Rehospitalisations initiative [33]. This program involved a state- based approach to reducing 30-day hospital readmissions. It involved 148 hospitals partnering with community based organisations with the aim of improving communication and the transition between health care providers. The intervention also comprised of multi-stakeholder, state-level steering committees. These committees coordinated programs throughout the State aligning partners and troubleshooting barriers to implementation [33]. The collaborative cross-continuum teams included health professionals from acute care, community health programs, Aged Care facilities, ambulatory care, social services, patient and family caregivers. Each hospital was expected to perform a comprehensive assessment of patients' needs post-discharge, provide patient and carer education, provide clear discharge information to the patient, carer and community provider and ensure early post-discharge follow-up for medical and non-medical services. At the time of writing the systematic review, results from STAAR were not published. The study was rated as a low quality of evidence due to a lack of information about their outcome data.

Hospital to home $(\mathbf{H} 2 \mathrm{H})$ The Hospital to Home $(\mathrm{H} 2 \mathrm{H})$ [34] Initiative provided a toolkit to clinicians to assist them in implementing evidence-based care from clinical guidelines, within their organisation. The toolkit contained evidence-based clinical information, webinars and recommended strategies and tools to improve evidence-based practice. The goal of the toolkit was for all patients to have a follow-up appointment/cardiac rehab referral within seven days of discharge, improved medication management, and information about early warning signs and a care plan to address them [34]. At the time of the conducting this literature search the only published article was an evaluation done by Bradley [35].

Bradley [35], undertook a survey of 537 hospitals enrolled in the $\mathrm{H} 2 \mathrm{H}$ program, to determine their resources for reducing heart failure readmissions. All of the hospitals reported monitoring their performance data in particular 30-day readmissions rates. Two thirds of the hospitals had a designated person or group to review unplanned readmissions that occurred within 30 days of discharge. On average, hospitals implemented less than half of the 10 recommended $\mathrm{H} 2 \mathrm{H}$ practices. Less than $3 \%$ of the hospitals, routinely used all 10 [35]. The $\mathrm{H} 2 \mathrm{H}$ programs was rated as low quality of evidence due to a lack of published information about their outcome data (Table 1).

\section{Transitional/community based care}

Most transitional care literature focussed on post-discharge heart failure programs and implementing single site specific interventions. Numerous meta-analyses have shown that heart failure programs reduce hospital readmissions and mortality [36-38]. Meta-analyses of heart failure programs found a large degree of heterogeneity between studies and no single intervention was able to be isolated to determine their effectiveness. Rather the effectiveness of many discharge programs was due to a bundle of interventions $[16,22,40,41]$. A quality improvement tool was developed from a national survey of heart failure programs and data from 573 patients enrolled in those programs [40]. The quality improvement tool showed that the more interventions implemented within a program the greater the improvement in patient outcomes. Patients participating in complex programs were $20 \%$ less likely to experience a hospital readmission and/or mortality (HR 0.80, $95 \% \mathrm{CI}$ $0.70-0.92)$ compared to less complex programs [40]. This study was rated with a high quality of evidence (Table 1).

The use of specialist heart failure nurses within the heart failure programs also improved patient outcomes [12]. Several meta-analyses of heart failure programs have shown an improvement in patient outcomes in programs where nurses are experienced in heart failure and have qualifications in a cardiac speciality and/or critical care. A randomised control trial of a heart failure program involving generic nurses with no cardiac experience found a $13 \%$ reduction in hospital readmissions [42] compared to meta-analyses involving heart failure nurses showing a $30 \%$ reduction in hospital readmissions [36, 43].

Jaarsma and colleagues [44] implemented a randomised controlled trial to determine the effect of low, moderate or high intensity, post-discharge follow up with a heart failure nurse. Low intensity follow-up or usual care comprised of an outpatient appointment with a Cardiologist within two months post-discharge and then every six monthly. Moderate follow-up consisted of usual care and nine outpatient appointments with a heart failure nurse. High intensity follow-up also consisted of usual care and weekly telephone calls and a home visit within the first month post-discharge, followed by additional telephone calls with the heart failure nurse, two home visits and two multidisciplinary appointments. They found that neither moderate nor intensive follow up by a heart failure nurse reduced the combined end points of heart failure death and hospitalization compared with usual care. At 
18 months, 411 patients (40\%) were readmitted because of heart failure or died from any cause [44]. There was no significant difference in heart failure readmission or mortality between the three groups: $42 \%$ in the control group, and $41 \%$ and $38 \%$ in the basic and intensive support groups, respectively ( $P=.73$ and $P=.52$, respectively) [44].

\section{Nurse-led medication titration}

Nurse-led medication titration in heart failure patients has been shown to improve patient outcomes whether in a clinic or in the community. Driscoll and colleagues [45] examined nurse-led titration of beta-adrenergic blockers by heart failure nurses in the community during a home visit. They recruited 484 patients diagnosed with HFrEF participating in 33 heart failure programs. The study found allcause hospitalisations and mortality was lower in patients participating in programs allowing nurse-led titration of beta-adrenergic blocking agents (HR 0.58, 95 \% CI 0.420.81 ) [45]. The study was assessed as a high quality of evidence (Table 1). Driscoll et al. [46] also implemented a randomised controlled trial of a nurse-led titration clinic for patients diagnosed with HFrEF. Patients were randomised to titration of beta-adrenergic blocking agents by a nurse in an outpatient clinic or follow up by their general practitioner for titration of these medications [46]. The nurse-led medication titration clinic resulted in a $50 \%$ reduction in time to optimal dose of beta-adrenergic blocking agents compared with optimisation of beta-adrenergic blocking agents by general practitioners $(90 \pm 14$ days vs $166 \pm 8$ days, $p<0.0005)$ [46]. Risk of bias was assessed as low (Table 2). A meta-analysis of nurse-led titration, regardless of the setting, found that patients participating in nurse-led titration of beta-adrenergic blocking agents and angiotensin converting enzyme inhibitors were $21 \%$ less likely to be readmitted for any cause (HR 0.79, 95 \% CI $0.36-0.72$ ) and $34 \%$ were less likely to die [47].

\section{Outpatient clinics}

Literature involving outpatient clinics was mainly concerned with a lack of follow-up post-discharge and the benefits of follow-up in a heart failure clinic compared to generalist clinics. A recent analysis of Medicare claims data in the USA, found that of the patients hospitalised for heart failure, $52 \%$ of patients did not have an outpatient visit [48].

Heart failure clinical guidelines recommend early follow-up within 7-10 days post-discharge [49-51]. GWTG-HEART FAILURE found the median percentage of patients who had early follow-up after discharge from the index hospitalization was $38.3 \%$ (interquartile range, $32.4 \%-44.5 \%$ ) [49]. There was a large degree of variation between hospitals for early outpatient follow-up after discharge. Patients who had higher early follow-up appointments had a lower risk of 30-day readmission [49]. This study was rated as a high quality of evidence (Table 2).
Another study implemented follow-up at a heart failure clinic, within three days post-discharge [50]. There was a reduction in heart failure readmission rate from $18 \%$ to $13 \%$ [50]. The heart failure service was then extended to include telemedicine, using basic videoconferencing for patients living in rural and remote areas. Heart failure readmissions for this group of patients was reduced from $18 \%$ to $10 \%$ over a six month period [50]. There was a low quality of evidence for this study mainly due to no adjustment for potential confounding variables (Table 1).

The Registry to Improve the Use of Evidence-Based Heart Failure Therapies in the Outpatient Setting (IMPROVE-HF) is a national registry and performance improvement program of 15381 patients with chronic HFrEF from 167 outpatient cardiology practices [51]. The IMPROVE-HF study found an increase in adherence in performance measures was significantly associated with improved survival [51]. This study was rated as a high quality of evidence (Table 1).

\section{Telemonitoring/telehealth}

Telemonitoring is another transitional care intervention, particularly for those patients who do not have access to a Cardiologist or heart failure nurse. Telemonitoring involves automated transmission of patient data to a central service and includes measures such as patient-measured weight, blood pressure, heart rate and heart rhythm. A study by Cleland and colleagues [6] found mortality rates at 12 months were lower in patients participating in telemonitoring (29\%) or regular telephone support from a nurse (27\%) compared with usual care (45\%). In contrast, Koehler and colleagues [52] found no differences in mortality between the telemonitoring and usual care groups over 12-28 months. Nine randomised controlled trials investigated the effect of telemonitoring on hospital readmission and/or mortality. The risk of bias associated with these studies was low in seven studies [52, 39, 53-57] and unclear in two $[58,59]$ (Table 2). There were also two non-randomised studies that implemented a telemonitoring system, one study was rated as low [61] quality due to the lack of controlling for potential confounders and the other study was rated as high [61].

The Chronic Heart Failure Assessment by Telephone (CHAT) study investigated the utility of a telephone-based automated telemedicine system for patients diagnosed with HFrEF and living in rural and remote Australia [53]. The participants were required to dial into the telemedicine system monthly. The patients were required to answer questions about their heart failure clinical status, medical management of their condition and social questions relevant to their heart failure status. Alerts were set up within the Telewatch system alerting the CHAT nurse via the Patient Watch Screen to follow up patients that reported pre specified signs or symptoms warranting intervention. In 
patients randomised to the telemedicine system there were fewer patients hospitalised for any cause (74 versus 114, adjusted HR 0.67 [95 \% CI 0.50-0.89], $p=0.006$ ). Also less patients died and/or were hospitalised (89 versus 124, adjusted HR 0.70 [95 \% CI 0.53-0.92], $p=0.011$ ), compared to the usual care group [53]. The risk of bias associated with this study was low (Table 2).

The 'telemonitoring in the management of heart failure' (TEMA-HF) study did find a significant difference in mortality but not in readmission rates [54]. They randomised 160 patients hospitalised with heart failure to usual care or an intervention group. Patients randomised to usual care received a cardiology outpatient clinic within two weeks of discharge. Patients in the intervention group were provided with a telemonitoring system to use at home with in-built alerts when the patient's vital signs fell below a predetermined level prompting follow up by a heart failure nurse, and a consultation service between the general practitioner and cardiologist concerning clinical management of the patient. At six months, all-cause mortality was significantly lower in the telemonitoring group compared to usual care (5 \% versus $17.5 \%$, respectively, $p=0.01$ ) but there was no significant difference in heart failure hospitalisations between the telemonitoring and usual care groups $(0.24$ versus 0.42 hospitalisations/patient, respectively, $p=0.06$ ) [54].

The Health Buddy Program integrated a telehealth system with care management [61]. The program had $15 \%$ lower risk-adjusted all-cause mortality (HR 0.85, 95 \% CI $0.74-0.98 ; P=.03$ ) and had reductions in the number of quarterly inpatient admissions from baseline to the study period that were $18 \%$ greater than those of matched controls during this same time period [61]. There was a high quality of evidence associated with this study (Table 1). The BEAT-HF study is currently underway [58]. Patients will be randomised into an intensive patient education group using the 'teach-back' method and receive instruction in using the telemonitoring equipment. Following hospital discharge, they will receive a series of nine scheduled health coaching telephone calls over 6 months from nurses located in a centralized call center. The nurses will call patients and patients' physicians in response to alerts generated by the telemonitoring system, based on predetermined parameters [58]. As results are currently not available the risk of bias associated with this study was unclear (Table 2).

A systematic review and meta-analysis of telemonitoring programs $[63,62]$ found a lower all-cause readmission rate and mortality for patients participating in a telemonitoring program. However, since that time, two large telemonitoring RCTs have found that telemonitoring had no effect on reducing hospital readmissions or mortality [52, 56]. Chaudhry [55] implemented an RCT of telemonitoring in 1653 patients recently admitted to hospital for acute decompensated heart failure. The telemonitoring program consisted of a telephone-based interactive voice response system that collected daily information about symptoms and weight that were reviewed by the patients' clinicians. Patients were asked to dial into the system daily. During each call patients were asked several questions about their general health and heart failure symptoms. Chaudhry [55] found no difference in hospital readmission and mortality between the telemonitoring group and usual care. The study was reported as a low risk of bias (Table 2).

Koehler and colleagues [52] also implemented a telemonitoring program involving the randomisation of 710 chronic heart failure patients to a telemonitoring program or usual care. Similar to Chaudhry et al. [55], this study was also rated as a low risk of bias (Table 2). The telemonitoring program consisted of: portable devices for ECG, blood pressure, and body weight measurements. Patients were required to undertake daily self-assessments and the data was transferred to the telemonitoring data centre. They found no significant difference in all-cause mortality or heart failure hospitalisation [52]. Pekmezaris and colleagues [56] also implemented a similar telemonitoring system and randomised 168 patients, post hospitalisation for heart failure, into usual care or telemonitoring groups. They found no significant differences in 30 and 90-day readmission rates between usual care and telemonitoring groups [56]. Schwarz and colleagues [59] also randomised 102 patients and their carers to usual care or telemonitoring and found no significant differences between the groups for hospital readmissions at 90 days post-discharge (13 versus 12 respectively, $p=0.6$ ) [60]. The risk of bias was assessed as unclear as only an abstract was available. Woodend and colleagues [57] also found a non-significant difference between their telemonitoring and usual care groups for hospital readmission at 90 days $(5.48 \%$ difference between groups, $p>0.05$ ) and at one year post-discharge $(-4.17 \%$ difference, $p>0.05)$ [57].

Angermann and colleagues [39] also found no significant differences in their primary endpoint of hospital readmission rates, between usual care and telemonitoring groups. Angermann et al. [39] randomised 715 patients hospitalised with acute decompensated heart failure into one of two groups: usual care consisted of discharge planning and follow up with a cardiologist within 7-10 days post-discharge (363 patients) or to HeartNetCare-HF (HNC) comprising of inpatient visits with a heart failure nurse, structured telephone-based monitoring system including blood pressure, pulse and symptoms, uptitration of key medication and access to specialist care as required (352 patients) [39]. All patients were followed up for 180 days. There was no significant difference in the composite endpoint of all-cause hospitalisation or mortality (HR, 1.02; $95 \%$ CI, 0.81, 1.30; $P=0.89$ ) [39]. There was a slightly higher rate of 
readmissions in the HNC group compared to usual care (119 versus 112 respectively) but this was not statistically significant between the groups [39].

\section{Discussion}

There was a paucity of studies that focussed on systems of care for heart failure with a primary outcome of readmission rates. Several studies recommended the implementation of a heart failure service or unit to manage heart failure patients regardless of the setting. Unfortunately, the translation of this evidence into clinical practice is poor, contributing to higher readmission and mortality rates $[12,64-66]$.

In primary care, several studies implemented a collaborative model of care for the management of patients diagnosed with heart failure. General practitioners are the cornerstone of managing heart failure patients in the community. However, there were only a few studies that were based in primary care. Difficulty in diagnosing heart failure due to the non-specific signs and symptoms can be challenging for general practitioners and may partly explain the under diagnosis of heart failure. Vilesca and colleagues [67] found that a general practitioner in primary care had a total of 10 guidelines that addressed diagnostics in heart failure. However, the criteria for diagnosis varied greatly [67]. This may contribute to a $12 \%$ misdiagnosis rate for heart failure when general practitioners are responsible for the initial diagnosis [68]. The paucity of randomised controlled trials in primary care, focussing on improving systems of care for heart failure patients, highlights the need for more research in this area.

The main driver in improving inpatient systems of care for heart failure has been the 30-day readmission quality performance indicator in the USA. As a consequence, several large national quality improvement programs and clinical registries have been implemented throughout the USA. These programs have been effective in improving the translation of clinical guidelines into practice. However, reducing 30-day readmissions remains elusive. This raises the question: are 30 day readmissions the appropriate benchmark to use for reimbursement and as an indicator of hospital quality? Focussing on 30 days readmissions may under estimate the burden of heart failure and perhaps aiming our interventions at reducing heart failure readmissions over a longer period of time would be more effective. Over the last few years, hospitalisations, length of stay and in-hospital mortality for heart failure, have all improved, however, 30 day readmissions have not. It is unclear if this is due to inherent problems with the clinical indicator or inadequate progress with improving discharge planning and transitional care. Due to the chronicity associated with heart failure, effective systems of care need to encompass an outcome measure of readmission rates greater than 30 days. In order to improve hospital readmissions for heart failure a national co-ordinated approach is vital, with national benchmarking and collaboration between health professionals, particularly focusing on improving systems of care for managing inpatient heart failure patients.

A smooth, safe and efficient transition from hospital to home is essential to avoid hospital readmissions. The challenge is ensuring a seamless transition from hospital to outpatient care to long-term community care whilst not compromising on quality or adherence to evidence-based practice and maintaining linkage with a heart failure specialist team. Transitional care incorporates heart failure programs in the community and outpatient clinics. There was a high level of evidence supporting the implementation of nurse-led medication titration clinics. A meta-analysis of nurse-led clinics for the titration of key therapeutic medications reduced hospital readmissions and mortality [47]. An outpatient clinic appointment within 7-10 days post-discharge was also associated with a lower risk of hospital readmission [49]. In particular, an early follow-up with a cardiologist and their general practitioner improved patient survival [18]. Several clinical registries have also been implemented to monitor the quality of outpatient care. They all report an improvement in adherence to guideline recommended therapy $[49,51]$.

Several transitional programs also included telemontioring or telehealth. However, due to conflicting results between large randomised controlled trials, more research is needed in this area. A meta-analysis incorporating recent conflicting randomised controlled trials is urgently warranted.

\section{Limitations}

The main limitation of this integrated review was the quality of studies. The majority of the studies were descriptive and conducted at a single centre with few multicentre randomised controlled trials. A metaanalysis of these studies was not conducted due to the heterogeneity of the interventions, variability in primary endpoints, length of follow-up and study design. In terms of the quality of the evidence, eight of the 17 nonrandomised studies were rated as low due to a lack of controlling for potential confounding variables so their results should be interpreted with caution. There were also two studies that had, to date, not published their outcome data so the quality of their evidence was also rated as low. However, it was important to include these studies in the review due to the innovative and potentially effective programs being implemented. Two of the six randomised controlled trials had their risk of bias assessed as unclear. In both of these studies only the abstract was available so full information to assess risk of bias was unable to be accessed. 


\section{Conclusion}

A suite of interventions, co-ordinated by a heart failure specialist workforce, are needed across the continuum of care to improve the translation of evidence into practice in patients diagnosed with heart failure. In primary care, collaborations between the general practitioner and cardiologist have been effective at improving evidencebased practice. During hospitalisation, quality improvement programs have improved the quality of inpatient care. In the transitional care phase, heart failure programs, nurse-led clinics, and early outpatient follow-up, reduced hospital readmissions. Importantly, there needs to be a seamless transition of care across the continuum with improved communication and co-ordination between services.

Clinical guidelines recommend evidence-based practice that improves patient outcomes. However, the translation of evidence into practice is lacking. More work needs to be done to bridge the evidence-practice gap to improve outcomes for heart failure patients and to reduce hospital readmissions.

\section{Appendix 1}

Table 3 Search strategies

\begin{tabular}{ll}
\hline Database searched & $\begin{array}{l}\text { Results } 31^{\text {st }} \text { July } \\
2015\end{array}$ \\
\hline MEDLINE, $1^{\text {st }}$ January 2008 to $31^{\text {st }}$ July 2015 & 145 \\
CINHAL , $1^{\text {st }}$ January 2008 to $31^{\text {st }}$ July 2015 & 21 \\
EMBASE, $1^{\text {st }}$ January 2008 to $31^{\text {st }}$ July 2015 & 107 \\
THE COCHRANE LIBRARY, Issue 7 of 12, July (2015). & 9 \\
$1^{\text {st } J a n u a r y ~ 2008 ~ t o ~} 31^{\text {st }}$ July 2015 & \\
Grey Literature $1^{\text {st }}$ January 2008 to $31^{\text {st }}$ July 2015 & 238 \\
Total (including duplicates) & 520 \\
\hline
\end{tabular}

1. Medline and Cinahl and Cochrane search strategy

\#1 "heart failure" OR "cardiac failure"

\#2 prevent" OR reduc* OR improv* OR avoid* OR readmi* OR recommend*

\#3 (\#1 AND \#2)

\#4 "care model" OR "model of care" OR "system" of care" OR "care management" OR "patient-cent" care" \#5 (\#3 AND \#4)

\#6 (emergency OR acute OR primary OR community OR after OR ambulatory OR transition* OR aged) N3 care

\#7 "acute hospital" OR "general practice"

\#8 (\#6 OR \#7)

\#9 (\#5 AND \#8)

2. EMBASE search strategy

\begin{tabular}{|c|c|}
\hline$\# 1$ & 'heart failure' \\
\hline \#2 & 'cardiac failure' \\
\hline \#3 & \#1 OR \#2 \\
\hline \#4 & prevent OR prevention \\
\hline \#5 & reduce OR reduction \\
\hline$\# 6$ & improve OR improvement \\
\hline \#7 & avoid OR avoided OR avoidance \\
\hline \#8 & readmit OR readmission OR readmissions \\
\hline \#9 & recommend OR recommendations \\
\hline \#10 & \#4 - \#9 OR \\
\hline \#11 & \#3 AND \#10 \\
\hline \#12 & 'care model' \\
\hline \#13 & 'model of care' \\
\hline \#14 & 'system of care' \\
\hline \#15 & 'systems of care' \\
\hline \#16 & 'care management' \\
\hline \#17 & 'patient centered care' \\
\hline \#18 & 'patient centred care' \\
\hline \#19 & $\# 12$ - \#18 OR \\
\hline \#20 & \#11 AND \#19 \\
\hline \#21 & (emergency NEAR/3 care) \\
\hline$\# 22$ & (acute NEAR/3 care) \\
\hline \#23 & (primary NEAR/3 care) \\
\hline \#24 & (community NEAR/3 care) \\
\hline \#25 & (after NEAR/3 care) \\
\hline \#26 & (ambulatory NEAR/3 care) \\
\hline \#27 & (transition NEAR/3 care) \\
\hline \#28 & (transitional NEAR/3 care) \\
\hline \#29 & (aged NEAR/3 care) \\
\hline \#30 & 'acute hospital' \\
\hline \#31 & 'general practice' \\
\hline \#32 & \#21 - \#31 OR \\
\hline \#33 & \#20 AND \#32 \\
\hline
\end{tabular}

3. Grey literature search strategy

Google Advanced :-

("heart failure" OR "cardiac failure") AND (policy OR guideline) AND (prevent OR prevention OR reduce OR reduction OR readmission OR improve OR improvement) AND ("care model" OR "model of care" OR "management systems" OR "system of care" OR "patient centered care" OR patient centred care")

- PDF and Microsoft Word document file types only

- .gov and .org domains 


\section{Appendix 2}

\section{Included studies of systems of care for heart failure}

Table 4 Included studies of systems of care for heart failure (excluding systematic reviews, meta-analyses and policy documents)

\begin{tabular}{|c|c|c|c|}
\hline Authors, year & Sample & Study design & Intervention \\
\hline \multicolumn{4}{|l|}{ Workforce } \\
\hline Zuily, 2010 [15] & $\begin{array}{l}3200 \text { patients admitted to } \\
\text { hospital with ADHF from } \\
1997 \text { to } 2007\end{array}$ & $\begin{array}{l}\text { Pre and post-test } \\
\text { design }\end{array}$ & $\begin{array}{l}\text { A heart failure unit was } \\
\text { implemented in } 2002 . \\
\text { All patients received an } \\
\text { outpatient appointment } \\
\text { with the unit within one } \\
\text { month post-discharge. The } \\
\text { visits included patient } \\
\text { education, assessment } \\
\text { with the Cardiologist and } \\
\text { up-titration of medications. } \\
\text { Patients were followed up } \\
\text { monthly with six weekly } \\
\text { education sessions. }\end{array}$ \\
\hline
\end{tabular}

Boom, 2012 [13] $\quad 7634$ patients hospitalized for

NICOR, 2012 [12]

Comin-Colet, 2014 [16]

Primary care

Lee, 2010 [18]

Rosstad, 2013 [17] hospital with heart failure

2083 patients admitted with ADHF to the hospital with a heart failure service compared to 54659 patients admitted to hospitals with no heart failure service
36504 patients admitted to ADHF who were participating in the EFFECT trial

Retrospective cohort study

UK national audit consisting of retrospective review of medical records

Retrospective cohort study with heart failure and were discharged from an ED in Ontario

19 clinicians participated in focus groups.

Outcomes

heart failure related

readmissions were reduced

from $21.7 \%$ in 2002 to

$15.6 \%$ in $2007(p<0.0001)$

Patients were divided as to whether they received cardiologist, general

Patients treated by general practitioners alone had higher risk of 30-day practitioner, or general (OR 1.50, 95 \% Cl 1.18-1.91) practitioner with cardiology and 1-year mortality consultation

(OR 1.29, $95 \%$ Cl 1.10-1.50)

Not applicable

In-patient mortality rates:

-Cardiology $8 \%$

-Gen Med $14 \%$

Outpatient clinics mortality

-Cardiology $18 \%$

-non Cardiology $31 \%$

Community follow-up

mortality

-Heart failure nurse $22 \%$

-non heart failure nurse $27 \%$

Patients admitted to the hospital with the heart

service wide heart filure program encompassing an inpatient service,

community service and a heart failure unit including a multidisciplinary specialist heart failure team.

failure service had a lower risk of death (hazard ratio $0.92,95 \%$ confidence interval, 0.86-0.97), $29 \%$

less likely to experience a readmission for any cause (95\% confidence interval, 0.66-0.76), and $14 \%$ lower risk of heart failure readmissions (95\% confidence interval, 0.80-0.94)

Retrospective cohort study

Patients were divided into one of three groups: collaborative follow-up with a cardiologist and primary care physician, primary care physician only follow-up, and no follow-up

Qualitative study, focus interviews
27 clinicians were identified as clinical champions to facilitate the implementation of clinical pathways. Focus groups were conducted to discuss the implementation of the care pathway.
Collaborative follow up with a cardiologist and primary care physician reduced 30 day mortality compared to primary care physician only (HR 0.79; $95 \% \mathrm{Cl} 0.63$ to 1.00 ).

A disease-orientated care pathway was not sustainable or appropriate to use in primary care. 
Table 4 Included studies of systems of care for heart failure (excluding systematic reviews, meta-analyses and policy documents) (Continued)

In-hospital studies

Williams, 2010 [21]

Tuso, 2014 [22]
Patients admitted to hospital with HFrEF. 50 patients were allocated to the historical group and 47 to the transitional care group

2076 hospital readmissions within 30 days post discharge from a hospitalisation for heart failure
Quasi-experimental design. All patients were followed up for 18 weeks.

Prospective cohort study

In-hospital education and follow-up arrangements either an appointment at the nurse-led clinic or home visits by the community heart failure nurse.

Implemented a heart failure "bundle" that included inpatient heart failure education, a home visit within $48 \mathrm{~h}$ of discharge, a follow-up appointment with a physician and a follow-up phone call from a heart failure care manager within 7 days of discharge.

In-hospital clinical audits/registries/quality improvement initiatives

Boutwell,

2011 [33]

(State Action on Avoidable

Rehospitalizations

initiative- STAAR

program)

Heidenreich

2012 [26]

(GWTG-HF

program)
148 hospitals throughout the US Quality improvement
program.

Quality improvement program. over 2093 US hospitals participate at least once in GWTG throughout the US
Hansen, 2013 [32]

BOOST program
11 hospitals throughout the US. In Feb 2014, 180 hospitals were participating. Patient numbers are not mentioned
Hospitals work in partnership with providers and community services that the hospital frequently uses to collaborate in improving communication and coordination during transition from the hospital to the next setting of care.

Registered hospitals receive access to GWTG toolkit specific for heart failure. The toolkit comprises of: initiation of evidence-based medications, implantation of appropriate device therapies, discharge education about heart failure, evaluation of left ventricular function, and post discharge follow-up appointment. Data is then entered into a web based system and each participating hospital receives site level patient data to identify those at risk of readmission.

Quality improvement program. Pre and post implementation design

The BOOST intervention consisted of a toolkit which contained: an implementation guide, project management tools, such as the Teach Back Training Curriculum, and PICO guidelines to evaluate the intervention; face-toface training and 12 months of expert mentoring and coaching and assistance to build a culture that supports organisational change to reduce hospital readmissions, also linking
30 day readmissions were lower in the transitional care group at $8 \%$ vs $14 \%$ in the historical group.

Readmissions rates were reduced from 19 to $15 \%$ over 30 -days $(p=0.03)$.

No results published to date

Hospitals participating in GWTG-HF had significantly higher documentation of the left ventricular ejection fraction $(93.4 \%$ versus nonparticipating hospitals (89\%), use of ACEI or angiotensin receptor antagonist (88.3\% versus $86.6 \%)$, and discharge instructions ( $74.9 \%$ versus $70.5 \%$ ).

After discharge, all-cause readmission at 30 days was $24.5 \%$ and mortality at 30 days after admission was $11.1 \%$.

30-day readmission was lower for GWTG hospitals $(-0.33 \% ; 95 \% \mathrm{Cl},-0.53 \%$ to $-0.12 \%)$.

The average rate of 30-day rehospitalization prior to implementation was $15 \%$ and $13 \% 12$ months later.

This was an absolute reduction of $2 \%$ and a relative reduction of $14 \%$. 
Table 4 Included studies of systems of care for heart failure (excluding systematic reviews, meta-analyses and policy documents) (Continued)

$\mathrm{H} 2 \mathrm{H}$ National

Quality Improvement

Initiative, 2015

[34] $(\mathrm{H} 2 \mathrm{H}$

program)

Transitional care

Jaarsma, 2008 [44]

Driscoll, 2011 [45]

Outpatient clinics

Fonarow,

2011 [51]

IMPROVE program
No data available

Quality improvement program. post hospitalisation for ADHF. Patients were assigned to 1 of 3 groups: a usual care group, a HF nurse follow-up post-discharge and intensive support by a HF nurse.

RCT
1023 patients were enrolled

with other participating

sites and data

management. Each site also

received project benchmark data and site level patient data.

The Hospital to Home $(\mathrm{H} 2 \mathrm{H})$ Initiative provides a toolkit to clinicians assist them in implementing evidence-based care from clinical guidelines, within their organisation.

The usual care group consisted of follow-up with a Cardiologist within two months post-discharge and then six monthly. Patients in group 2 had nine clinic visits with a HF nurse post-discharge, in addition to the usual care visits. Education about HF and self-management strategies were provided during the HF nurse clinic visits.

Group 3 received the same visits as Group 2 and then also received one home visit and weekly telephone contact during the first month post-discharge. After the first month, they also received two additional home visits and two visits with the multidisciplinary team.

All patients were follow up for 18 months.

Thirty-three community-based

Cohort study. All patients were followed up for six months.
Patient outcomes in programs with nurse-led titration (NLT) of betablockers were compared with those in programs that did not allow such titration. systolic dysfunction and $>1$ earlier hospitalization for ADHF

No data available

Neither moderate nor intensive follow up by a HF nurse reduced the combined end points of HF death and hospitalization compared with usual care. At 18 months, 411 patients (40\%) were readmitted because of HF or died from any cause: $42 \%$ in the control group, and $41 \%$ and $38 \%$ in the basic and intensive support groups, respectively (hazard ratio, 0.96 and 0.93 , respectively; $P=.73$ and $P=.52$, respectively).

All-cause mortality occurred in $29 \%$ of patients in the control group, and there was a trend toward lower mortality in the intervention groups combined $(P=.18)$.

At 6 months, $47 \%$ of patients participating in UC programs had no change in dosage from baseline to 6 months, compared with $39 \%$ of patients participating in NLT programs. Patients in NLT programs were also more likely to be prescribed at target dose (48\% NLT vs $36 \%$ UC). The composite of all-cause hospitalizations and mortality was lower in patients participating in programs allowing NLT (HR $0.58,95 \%$ Cl 0.42-0.81).

Prospective clinical registry
No invention as it was a clinical registry
Adherence to a range of guideline-recommended heart failure therapies ranging from $30-80 \%$. An increase in adherence in performance measures was significantly associated with improved survival 
Table 4 Included studies of systems of care for heart failure (excluding systematic reviews, meta-analyses and policy documents) (Continued)

Driscoll, 2014 [46]

13 patients diagnosed with HFrEF were randomised to usual care and 12 to the NLT clinic

Fenner, 2014 [50]

Patients admitted to hospital with ADHF.

Piette, 2008 [60]

Schwarz, 2008 [59]

$\mathrm{RCT}$

Patients were randomised to optimisation of $\mathrm{BB}$ in a nurse-led titration (NLT)

clinic, led by a nurse specialist with the support of a cardiologist in a heart failure clinic, or by their primary care physician

No data was available. Patients were seen in hospital and given education by a heart failure nurse. Patients had an appointment scheduled within three days postdischarge to attend the Heart Success Transition Clinic (HSTC). They were seen in the clinic for 4-6 weeks and then referred back to primary care. A telemedicine clinic was also available for patients living in rural and remote areas.

52 heart failure patients and their carers

Prospective cohort study

$\mathrm{RCT}$

102 patients and their carers post discharge from hospital with ADHF
Telemonitoring using informal carers. The CarePartner Program included an automated telephonic heart failure assessment and behaviour change service.

Patients received weekly calls from the system and reported information about their health and self-care using their touchtone telephone.

Care nurse managers were notified when a patient reported an urgent medical condition.

Participants were interviewed within 10 days post discharge and 90 days later. The patient recorded their weight and vital signs daily via the telemonitoring system and responded to questions about symptoms. The data from the telemonitoring system was monitored daily by a heart failure nurse.

Usual care consisted of follow-up with their primary physician or cardiologist.
The time to maximum dose was shorter in the NLT group compared to the UC group ( $90 \pm 14 \mathrm{vs}$ $166 \pm 8$ days, $p<0.0005)$. At six months, in the NLT group there were $82 \%$ on high dose and $9 \%$ on low dose beta-adrenergic receptor blocker compared to the UC group with $42 \%$ patients reaching maximum dose and $42 \%$ patients on low dose.

HSTC found a reduction in heart failure readmission rate from $17.92 \%$ to $13.49 \%$. The telemedicine clinic reduced heart failure readmissions from $18 \%$ to $10 \%$ over a six month period

$75 \%$ of patients had made changes in their self-care as a result of the intervention.

No significant difference in hospital readmissions or mortality 
Table 4 Included studies of systems of care for heart failure (excluding systematic reviews, meta-analyses and policy documents) (Continued)

Woodend,

2008 [57]

Chaudhry,

2010 [55]

Koehler, 2011 [52]

Angermann,

2012 [39]
121 patients admitted with HF and 128 patients admitted with angina

1653 patients admitted with

ADHF

710 chronic heart failure patients

715 patients hospitalised with systolic heart failure
$\mathrm{RCT}$

$\mathrm{RCT}$

90 day follow-up

$\mathrm{RCT}$

$\mathrm{RCT}$

All patients were followed up for 180 days.
The telemonitoring system

consisted of video

conferencing and phone

transmission of weight, vital

signs and ECG. The patient

was required to record

their weight and vital signs

via the telemonitoring

system daily and weekly

video conferencing with

the heart failure nurse.

Usual care consisted of

follow-up with their

primary physician or

cardiologist.

The telemonitoring group was instructed to make daily, toll-free calls to the system. During each call, patients heard a series of questions about general health and heart-failure symptoms.

The protocol required the sites to contact any patient whose response generated an alert.

\section{The telemonitoring program consisted of: portable devices for ECG, blood pressure, and body weight measurements. Patients were required to undertake daily self- assessments and the data was transferred to the telemonitoring data centre. Usual care consisted of follow-up with their primary physician or cardiologist.}

The telemonitoring intervention consisted of: inhospital visit, structured telephone follow-up addressing heart failure symptoms, medications, health systems utilisation and psychological wellbeing; titration of heart failure medication, and increased access to specialist care. Contact was weekly for one month and then individualised based on NYHA class. Usual care consisted of follow-up with their primary physician or cardiologist.
No significant difference in hospital readmissions or mortality

No difference in mortality or heart failure hospitalisations between groups.

No difference in mortality or hospitalisations between groups. 
Table 4 Included studies of systems of care for heart failure (excluding systematic reviews, meta-analyses and policy documents) (Continued)

Dendale,

2012 [54]
160 patients hospitalised with ADHF from seven hospitals
RCT Six month follow up

Patients were asked to transmit their weigh and vital signs daily via the telemonitoring system. When these measurements exceeded preset limits for two consecutive days an automatic email alert was sent to their primary physician and heart failure clinic. Their primary physician was to contact the patient when they received an alert and the heart failure nurse would follow up with the patient 1-3 days post alert.

Usual care and telemonitoring patients were all seen in the heart failure clinic 2 weeks post-discharge. Usual care consisted of follow-up with their primary physician post-discharge.

Pekmezaris, 2012 [56]

Baker, 2013 [61]
168 patients hospitalised with a primary or secondary diagnosis of heart failure
$\mathrm{RCT}$

All patients were followed up for 90 days.
The telehealth intervention consisted of two videobased nursing visits (including weighs and monitoring of vital signs) and one visit with a community heart failure nurse within the first two weeks post-discharge. The frequency of the telehealth visits was determined the heart failure nurse based on patient needs and continued for 90 days post-discharge.

Usual care consisted of follow-up with a community heart failure nurse.

Retrospective The Health Buddy Program matched cohort study. which integrated a Two years of follow-up content-driven telehealth system with care management.
All-cause mortality was significantly lower in the TM group as compared with the UC group ( $5 \%$ vs. $17.5 \%, P=0.01$ ).

The number of heart failure readmissions per patient showed a trend (0.24 vs. 0.42 hospitalizations/ patient, $P=0.06$ ) in favour of TM.
No significant difference in hospital readmissions or mortality
3534 patients with chronic heart failure, chronic obstructive pulmonary disease or diabetes mellitus. Intervention group $(n=1,767)$ and in the matched control group $(n=1,767)$
Krum, 2013 [53]

CHAT study
405 patients diagnosed with heart failure. 217 patients were randomised to usual care by their primary physican and 188 to the intervention group. randomisation at level of ongoing support by of General Practitioner. touchtone telephone using All patients were followed up for 12 months the 'TeleWatch' system. Patients were required to dial in monthly to receive advice about the management of their heart
The Health Buddy Program had $15 \%$ lower riskadjusted all-cause mortality (HR 0.85, 95 \% Cl 0.74-0.98) and reductions in inpatient readmissions during the study period that were $18 \%$ greater than those of matched controls during this same time period $(-0.035$ vs -0.003 ; difference-in-differences $=$ $-0.032,95 \% \mathrm{Cl}=-0.054$ to -0.010 ).

Fewer patients hospitalised for any cause (74 versus 114, adjusted HR 0.67, $95 \%$ Cl 0.50-0.89) and who died or were hospitalised (89 versus 124 , adjusted HR 0.70 (95\% Cl 0.53-0.92), in the intervention group vs 
Table 4 Included studies of systems of care for heart failure (excluding systematic reviews, meta-analyses and policy documents) (Continued)

\begin{tabular}{|c|c|c|c|c|}
\hline & & & $\begin{array}{l}\text { failure and to complete } \\
\text { education modules about } \\
\text { the management of heart } \\
\text { failure at home. Patients } \\
\text { also had access to heart } \\
\text { failure specialist nurse via } \\
\text { the Telewatch system. }\end{array}$ & $\begin{array}{l}\text { usual care group, } \\
\text { respectively. }\end{array}$ \\
\hline Black, 2014 [58] & No data available & Multicentre RCT & $\begin{array}{l}\text { Patients in the intervention } \\
\text { group will receive intensive } \\
\text { patient education using the } \\
\text { 'teach-back' method and } \\
\text { receive instruction in using } \\
\text { the telemonitoring } \\
\text { equipment. Following } \\
\text { hospital discharge, they will } \\
\text { receive a series of nine } \\
\text { scheduled health coaching } \\
\text { telephone calls over } \\
6 \text { months from nurses } \\
\text { located in a centralized call } \\
\text { center. The nurses also will } \\
\text { call patients and patients' } \\
\text { physicians in response to } \\
\text { alerts generated by the } \\
\text { telemonitoring system, } \\
\text { based on predetermined } \\
\text { parameters. }\end{array}$ & $\begin{array}{l}\text { No published results to } \\
\text { date }\end{array}$ \\
\hline
\end{tabular}

ADHF acute decompensated heart failure, OR odds ratio, $H R$ hazard ratio, $\mathrm{Cl}$ confidence intervals, $A C E l$ angiotensin converting enzyme inhibitors, $H F r E F$ heart failure with reduced ejection fraction, HTM home telemonitoring, NTS nurse telephone support

\section{Abbreviations}

BOOST: Better outcomes for older adults through safe transitions; CHAT: Chronic heart failure assessment by telephone; GWTG: Get with the guidelines; HFpEF: Heart failure with preserved ejection fraction; HFrEF: Heart failure with reduced ejection fraction; HNC: HeartNetCare; HR: Hazard ratio; IMPROVE: Improve the use of evidence-based heart failure therapies in the outpatient setting; NOS: Newcastle-Ottawa Scale; OR: Odds ratio;

RCT: Randomised controlled trial; RR: Relative risk; STAAR: State action on avoidable rehospitalisations; TEMA-HF: Telemonitoring in the management of heart failure

\section{Acknowledgements}

Andrea Driscoll was supported by a Heart Foundation Future Leader fellowship 100472 from the National Heart Foundation of Australia. I would also like to acknowledge the contribution of members of the Heart Failure Expert Advisory Group committee: Kath Cowie, John Cuthbert, Hella Parker, and Bill Stavreski.

\section{Funding}

This project was funded by the National Heart Foundation of Australia.

\section{Availability of data and materials}

Patient level data has not been used. Not applicable.

\section{Authors' contributions}

Authors AD, SM and RK developed the search strategy and were responsible for interpretation of the data. All authors contributed to the manuscript and have seen and agreed to the final contents of the article. All authors met the criteria for authorship.

\section{Competing interest}

The authors declare that they have no competing interests.

\section{Consent for publication}

All authors have reviewed and consented to publication of the paper.
Ethics approval and consent to participate Not applicable.

\section{Author details}

${ }^{1}$ Deakin University, Locked Bag 20000, Geelong, VIC 3220, Australia. ${ }^{2}$ Heart

Foundation (Victoria), Level 12, 500 Collins st, Melbourne 3000, Australia.

${ }^{3}$ School of Rural Health, Monash University, Bendigo, Victoria, Australia.

${ }^{4}$ Monash Health, Clayton, Melbourne, Australia. ${ }^{5}$ Cardiology Department, Western Health, Gordon Street, Footscray, 3011 Melbourne, Australia. ${ }^{6}$ Monash Health, Monash Health Community, Dandenong, Melbourne, Australia. ${ }^{7}$ Department of Cardiology, University of Melbourne and Austin Health, Burgundy St Heidelberg, 3081 Melbourne, Australia. ${ }^{8}$ Cardiology Department, Bendigo Health, Victoria, Australia. ${ }^{9}$ St Vincent's Hospital, Victoria parade, Melbourne, Australia.

Received: 21 May 2016 Accepted: 28 September 2016

Published online: 11 October 2016

\section{References}

1. Lloyd-Jones DM, Larson MG, Leip EP, et al. Lifetime risk for developing congestive heart failure: the Framingham Heart Study. Circulation. 2002;106:3068-72.

2. Nieminen MS, Brutsaert D, Dickstein K, Drexler H, Follath F, Harjola VP, Hochadel M, Komajda M, Lassus J, Lopez-Sendon JL, Ponikowski P, Tavazzi $L$, on behalf of the EuroHeart Survey Investigators. EuroHeart Failure Survey II (EHEART FAILURES II): a survey on hospitalized acute heart failure patients: description of population. Eur Heart J. 2006;27:2725-36.

3. Bueno H, Ross JS, Wang Y, Chen J, Vida'n MT, Normand SLT, Curtis JP, Drye EE, Lichtman JH, Keenan PS, Kosiborod M, Krumholz HM. Trends in Length of Stay and Short-term Outcomes Among Medicare Patients Hospitalized for Heart Failure, 1993-2006. JAMA. 2010;303(21):2141-7.

4. Kociol RD, Hammill BG, Fonarow GC, et al. Generalizability and longitudinal outcomes of a national heart failure clinical registry: Comparison of Acute Decompensated Heart Failure National Registry (ADHERE) and non-ADHERE Medicare beneficiaries. Am Heart J. 2010;160:885-92. 
5. Maggioni AP, Dahlstrom U, Filippatos G, et al. EURObservational Research Programme: the Heart Failure Pilot Survey (ESC-HEART FAILURE Pilot). Eur J Heart Fail. 2010;12:1076-84.

6. Cleland JG, Louis AA, Rigby AS, Janssens U, Balk AH. Noninvasive home telemonitoring for patients with heart failure at high risk of recurrent admission and death: the Trans-European Network-Home-Care Management System (TEN-HMS) study. J Am Coll Cardiol. 2005;45:1654-64.

7. Maggioni AP, Dahlstrom U, Filippatos G, et al. EURObservational Research Programme: regional differences and 1-year follow-up results of the Heart Failure Pilot Survey (ESC-HEART FAILURE Pilot). Eur J Heart Fail. 2013;15:808-17.

8. Moher D, Liberati A, Tetzlaff J, Altman DG. Preferred reporting items for systematic reviews and meta-analyses: the PRISMA statement. BMJ. 2009:339:b2535.

9. Lefebvre C, Manheimer E, Glanville J. Chapter 6: Searching for studies. In: Higgins JPT, Green S, editors. Cochrane Handbook for Systematic Reviews of Interventions Version 5.1.0 [updated March 2011]. The Cochrane Collaboration; 2011. Available from www.cochrane-handbook.org. Accessed 2 Nov 2015

10. Wells GA, Shea B, O'Connell D, et al. The Newcastle-Ottawa Scale (NOS) for assessing the quality of nonrandomised studies in meta-analyses. Cochrane Library. 2014. http://www.ohri.ca/programs/clinical_epidemiology/oxford. htm. Accessed 5 Sept 2015.

11. Higgins JPT, Green S, editors. Cochrane Handbook for Systematic Reviews of Interventions Version 5.1.0 [updated March 2011]. The Cochrane Collaboration; 2011. Available from www.cochrane-handbook.org. Accessed 2 Nov 2015.

12. McDonagh TA, Cleland J, Dargttie H, Whittaker T, Standing M, Mitchell P, Cunningham D. National Heart Failure report: April 2010-March 2011. London: NICOR; 2012.

13. Boom NK, Lee DS, Tu JV. Comparison of processes of care and clinical outcomes for patients newly hospitalized for heart failure attended by different physician specialists. Am Heart J. 2012;163:252-9.

14. Fonseca C, Ceia F, Sarmento PM, et al. Translating guidelines into clinical practice: benefits of an acute heart failure unit. Rev Port Cardiol. 2007;26:1111-28

15. Zuily $S$, Jourdain $P$, Decup $D$, et al. Impact of heart failure management unit on heart failure-related readmission rate and mortality. Arch Cardiovasc Dis. 2010;103:90-6

16. Comín-Colet J, Verdú-Rotellar JM, Vela E, Clèries M, Bustins M, Mendoza L, Badosa N, Cladellas M, Ferré S, Bruguera J. Efficacy of an integrated hospitalprimary care program for heart failure: a population-based analysis of 56,742 patients. Revista Española De Cardiología (English Ed). 2014;67(4):283-93.

17. Roostad T, Garåsen H, Steinsbekk A, Sletvold O, Grimsmo A. Development of a patient-centred care pathway across healthcare providers: a qualitative study. BMC Health Serv Res. 2013;13:121.

18. Lee DS, Stukel TA, Austin PC, Alter DA, Schull MJ, You JJ, Chong A, Henry D, Tu JV. Improved outcomes with early collaborative care of ambulatory heart failure patients discharged from the Emergency Department. Circulation. 2010;122:1806-14.

19. Hansen LO, Young RS, Hinami K, Leung A, Williams MV. Interventions to Reduce 30-Day Rehospitalization: A Systematic Review. Ann Intern Med. 2011:155:520-8

20. Kul S, Barbieri A, Milan E, Montag I, Vanhaecht K, Panella M. Effects of care pathways on the in-hospital treatment of heart failure: a systematic review. BMC Cardiovasc Disord. 2012;12:81.

21. Williams SC, Schmaltz SP, Morton DJ, Koss RG, Loeb JM. Quality of care in U. S. hospitals as reflected by standardized measures, 2002-2004. N Engl J Med. 2005;353(3):255-64

22. Tuso P, Watson HL, Garofalo-Wright L, Lindsay G, Jackson A, Taitano M, Koyama S, Kanter M. Complex case conferences associated with reduced hospital admissions for high-risk patients with multiple comorbidities. The Permanente Journal. 2014;18(1):38-42. doi:10.7812/tpp/13-062.

23. Fonarow GC, Yancy CW, Heywood JT. Adherence to heart failure quality-ofcare indicators in US hospitals: analysis of the ADHERE Registry. Arch Intern Med. 2005:165:1469-77.

24. Fonarow CG, Abraham WT, Albert NM, Stough WG, Gheorghiade M, Greenberg BH, O'Connor CM, Pieper K, Sun JL, Yancy CW, Young JB, for the OPTIMIZE-HEART FAILURE Investigators and Hospitals Influence of a Performance-Improvement Initiative on Quality of Care for Patients Hospitalized With Heart Failure. Results of the Organized Program to Initiate Lifesaving Treatment in Hospitalized Patients With Heart Failure (OPTIMIZEHEART FAILURE). Arch Intern Med. 2007;167(14):1493-502.
25. Maeda JLK. Evidence-Based Heart Failure Performance Measures and Clinical Outcomes: A Systematic Review. J Cardiac Fail. 2010;16:411-8.

26. Heidenreich PA, Hernandez AF, Yancy CW, Liang L, Peterson ED, Fonarow GC. Get With The Guidelines Program Participation, Process of Care, and Outcome for Medicare Patients Hospitalized With Heart Failure. Circ Cardiovasc Qual Outcomes. 2012:5:37-43.

27. Ponikowski P, Anker SD, AlHabib KF, Cowie MR, Force TL, Hu S, Jaarsma T, Krum H, Rastogi V, Rohde LE, Samal UC, Shimokawa H, Siswanto BB, Sliwa K, Filippatos G. Heart failure Preventing disease and death worldwide. London: European Society of Cardiology; 2014.

28. Komajda $\mathrm{M}$, et al. The EuroHeart Failure Survey Programme-a survey on the quality of care among patients with heart failure in Europe. Part 2: Teatment. Eur Heart J. 2003:24:464-74.

29. GWTG_http://www.heart.org/HEARTORG/HealthcareResearch/ GetWithTheGuidelinesHEARTFAILUREStroke/ GetWithTheGuidelinesHeartFailureHomePage/Get-With-The-GuidelinesHeart-Failure-Home-Page_UCM_306087_SubHomePage.jsp

30. Hernandez AF, Fonarow GC, Liang L, Heidenreich PA, Yancy CW, Peterson ED. The Need for Multiple Measures of Hospital Quality: Results From the Get With The Guidelines-Heart Failure Registry of the American Heart Association. Circulation. 2011:124:712-9.

31. Heidenreich PA, Lewis WR, LaBresh KA, Schwamm LH, Fonarow GC. Hospital performance recognition with the Get With The Guidelines Program and mortality for acute myocardial infarction and heart failure. Am Heart J. 2009;158:546-53.

32. Hansen LO, Greenwald JL, Budnitz T, Howell E, Halasyamani L, Maynard G, Vidyarthi A, Coleman EA, Williams MV. Project BOOST: Effectiveness of a Multihospital Effort to Reduce Rehospitalization. J Hosp Med. 2013;8:421-7.

33. Boutwell $A E$, Johnson MB, Rutherford $P$, Watson SR, Vecchioni N, Auerbach BS, Griswold P, Noga P, Wagner C. An Early Look At A Four-State Initiative To Reduce Avoidable Hospital Readmissions. Health Aff. 2011;30(7):1272-80.

34. $\mathrm{H} 2 \mathrm{H}$ National Quality Improvement Initiative. Available at: http://cvquality. acc.org/Initiatives/H2H.aspx. Accessed June 2012.

35. Bradley E, Curry L, Horwitz LI, Sipsma H, Thompson JW, Elma MA, Walsh MN, Krumholz HM. Contemporary Evidence About Hospital Strategies for Reducing 30-Day Readmissions. A National Study. J Am Coll Cardiol. 2012:60:607-14.

36. McAlister FA, Stewart S, Ferrua S, McMurray JJV. Multidisciplinary strategies for the management of heart failure patients at high risk for readmission: A systematic review of randomised trials. J Am Coll Cardiol. 2004;44(4):810-9.

37. Phillips $\mathrm{CO}$, Singa RM, Rubin HR, Jaarsma T. Complexity of program and clinical outcomes of heart failure disease management incorporating specialist nurse-led heart failure clinics. A meta-regression analysis. Eur J Heart Fail. 2005;7:333-41.

38. Whellan DJ, Hasselblad V, Peterson E, O'Connor CM, Schulman KA. Metaanalysis and review of heart failure disease management randomised controlled clinical trials. Am Heart J. 2005;149:722-9.

39. Angermann CE, Stork S, Gelbrich G, et al. Mode of action and effects of standardized collaborative disease management on mortality and morbidity in patients with systolic heart failure: the Interdisciplinary Network for Heart Failure (INH) study. Circ Heart Fail. 2012;5:25-35.

40. Driscoll A, Tonkin A, Stewart A, Thompson D, Worrall-Carter L, Hare DL, Davidson PM, Riegel B, Mulvany C, Stewart S. Does more equal less: Complexity of management predicts subsequent outcomes in a prospective cohort study of 573 heart failure patients in Australia. J Clin Nurs. 2013;22(11-12):1629-38.

41. Leppin AL, Gionfriddo MR, Kessler M, Brito JP, Mair FS, Gallacher K, Wang Z, Erwin PJ, Sylvester T, Boehmer K, Ting HH, Murad MH, Shippee ND, Montori VM. Preventing 30-Day Hospital Readmissions A Systematic Review and Meta-analysis of Randomized Trials. JAMA Intern Med. 2014;174(7):1095-107. doi:10.1001/jamainternmed.2014.1608. Published onlineMay 12, 2014.

42. Naylor MD, Brooten DA, Campbell RL, Maislin G, Cauley KM, Schwartz JS. Transistional care of Older Adults Hospitalised with Heart Failure: A Randomised, Controlled Trial. JAGS. 2004;52:675-84.

43. Sochalski J, Jaarsma T, Krumholz HM, Laramee A, McMurray JJV, Naylor MD, et al. What works in chronic care management: the case of heart failure. Health Affairs (Project Hope). 2009;28(1):179-89. doi:10.1377/hlthaff.28.1.179.

44. Jaarsma T, van der Wal MHL, Lesman-Leegte I, Luttik M, Hogenhuis J, Veeger NJ, Sanderman R, Hoes AW, van Gilst WH, Lok DJA, Dunselman PHJM, Tijssen JGP, Hillege HL, van Veldhuisen DJ, for the Coordinating Study Evaluating Outcomes of Advising and Counseling in Heart Failure (COACH) Investigators. Effect of Moderate or Intensive Disease Management Program on Outcome in Patients With Heart Failure: Coordinating Study 
Evaluating Outcomes of Advising and Counseling in Heart Failure (COACH). Arch Intern Med. 2008;168(3):316-24.

45. Driscoll A, Krum H, Wolfe R, Tonkin A. Nurse-led titration of beta-blockers can improve outcomes in chronic heart failure patients in the community. J Card Fail. 2011;17:224-30.

46. Driscoll A, Srivastava P, Toia D, Gibcus J, Hare DL. Effectiveness of a specialist nurse-led titration clinic on beta-blocker therapy in patients with CHF: The MAXIMISE study. BMC Res Notes. 2014;7:668. doi:10.1186/1756-0500-7-668.

47. Driscoll A, Currey J, Tonkin A, Krum H. Nurse-led titration of angiotensin converting enzyme inhibitors, beta-adrenergic blocking agents and angiotensin receptor blockers for patients with left ventricular systolic dysfunction Review. Cochrane Database Syst Rev. 2015. In press.

48. Jencks SF, Williams MV, Coleman EA. Rehospitalisations among patients in the Medicare fee-for-service program. N Engl J Med. 2009;360:1418-28.

49. Hernandez AF, Greiner MA, Fonarow GC, Hammill BG, Heidenreich PA, Yancy CW, Peterson ED, Curtis LH. Relationship Between Early Physician Follow-up and 30-Day Readmission Among Medicare Beneficiaries Hospitalized for Heart Failure. JAMA. 2010;303(17):1716-22.

50. Fenner DJ, Gulati SK, Cloninger K, Emig ME. Reducing Heart Failure Admissions Through Heart Success Transitional Care Model. J Card Fail. 2014;20(8):S12.

51. Fonarow GC, Albert NM, Curtis AB, Gheorghiade M, Heywood JT, Liu Y, Mehra MR, O'Connor CM, Reynolds D, Walsh MN, Yancy CW. Associations Between Outpatient Heart Failure Process-of-Care Measures and Mortality. Circulation. 2011;123:1601-10.

52. Koehler F, Winkler S, Schieber M, et al. Telemedical Interventional Monitoring in Heart Failure Investigators. Impact of remote telemedical management on mortality and hospitalizations in ambulatory patients with chronic heart failure: the telemedical interventional monitoring in heart failure study. Circulation. 2011;123:1873-80.

53. Krum H, Forbes A, Yallop J, Driscoll A, Croucher J, Chan B, Clark R, Davidson PA, Huynh L, Kasper E, Hunt D, Budd L, Egan H, Stewart S, Piterman L, Tonkin A. Telephone Support to Rural and Remote Patients with Heart Failure; the Chronic Heart failure Assessment by Telephone (CHAT) study. Cardiovasc Ther. 2013;31(4):230-7.

54. Dendale P, De Keulenaer G, Troisfontaines P, Weytjens C, Mullens W, Elegeert I, Ector B, Houbrechts M, Willekens K, Hansen D. Effect of a telemonitoring-facilitated collaboration between general practitioner and heart failure clinic on mortality and rehospitalization rates in severe heart failure: the TEMA-HF 1 (TElemonitoring in the MAnagement of Heart Failure) study. Eur J Heart Fail. 2012;14:333-40. doi:10.1093/eurjhf/hfr144.

55. Chaudhry SI, Mattera JA, Curtis JP, Spertus JA, Herrin J, Lin Z, Phillips CO, Hodshon BV, Cooper LS, Krumholz HM. Telemonitoring in patients with heart failure. N Engl J Med. 2010;363:2301-9.

56. Pekmezaris R, Mitzner I, Pecinka KR, Nouryan CN, Lesser ML, Siegel M, Swiderski JW, Moise G, Younker R, Smolich K. The Impact of Remote Patient Monitoring (Telehealth) upon Medicare Beneficiaries with Heart Failure. Telemedicine DICINE and e-HEALTH. 2012;18(2):101-8.

57. Woodend AK, Sherrard H, Fraser M, Stuewe L, Cheung T, Struthers C. Telehome monitoring in patients with cardiac disease who are at high risk of readmission. Heart Lung. 2008;37:36-45.

58. Black JT, Romano PS, Sadeghi B, Auerbach AD, Ganiats TG, Greenfield S, Kaplan SH, Ong MK, BEAT-HF Research Group. A remote monitoring and telephone nurse coaching intervention to reduce readmissions among patients with heart failure: Study protocol for the Better Effectiveness After Transition - Heart Failure (BEAT-HEART FAILURE) randomized controlled trial. Trials. 2014;15(1):124. http://www.trialsjournal.com/content/15/1/124.

59. Schwarz KA, Mion LC, Hudock D, Litman G. Telemonitoring of Heart Failure Patients and Their Caregivers: A Pilot Randomized Controlled Trial. Prog Cardiovasc Nurs. 2008;23:18-26.

60. Piette JD, Gregor MA, Share D, Heisler M, Bernstein SJ, Koelling T, Chan P. Improving heart failure self-management support by actively engaging out-ofhome caregivers: results of a feasibility study. Congest Heart Fail. 2008;14(1):12-8.

61. Baker LC, MacAulay DS, Sorg RA, Diener MD, Johnson SJ, Birnbaum HG. Effects of care management and telehealth: A longitudinal analysis using medicare data. J Am Geriatr Soc. 2012;61(9):1560-7.

62. Chaudhry SI, Phillips CO, Stewart S, Riegel BJ, Mattera JA, Jerant AF, et al. Telemonitoring for patients with Chronic Heart Failure:A systematic review. J Card Fail. 2007;13(1):56-62.

63. Inglis SC, Clark RA, MCAlister FA, Stewart S, Cleland JGF. Which components of heart failure programmes are effective? A systematic review and metaanalysis of the outcomes of structured telephone support or telemonitoring as the primary component of chronic heart failure management in 8232 patients: Abridged Cochrane Review. Eur J Heart Fail. 2011;12:1028-40.

64. National Institute for Health Care Excellence (NICE). Acute heart failure: diagnosing and managing acute heart failure in adults. NICE clinical guideline 187. London: NICE; 2014. Available at: https://www.nice.org.uk/ guidance/cg187.

65. McDonagh TA, Blue L, Clark AL, Dahlstrom U, Ekman I, Lainscak M, McDonald K, Ryder M, Stromberg A, Jaarsma T, on behalf of Heart Failure Association Committee on Patient Care. European Society of Cardiology Heart Failure Association Standards for delivering heart failure care. Eur J Heart Fail. 2011;13:235-41.

66. Albert NM, Barnason S, Deswal A, Hernandez A, Kociol R, Lee E, Paul S, Ryan CJ, White-Williams C, on behalf of the American Heart Association Complex Cardiovascular Patient and Family Care Committee of the Council on Cardiovascular and Stroke Nursing, Council on Clinical Cardiology, and Council on Quality of Care and Outcomes Research. Transitions of Care in Heart Failure: A Scientific Statement From the American Heart Association. Circ Heart Fail. 2015;8:000. doi:10.1161/HHEARTFAILURE.0000000000000006

67. Vilaseca J, Dedeu T, de Graaf P, Hobbs R, Muth C, Martensson J, LopezAlcazar P, Scherer M. Chronic heart failure: the role of primary care position paper of the European Forum for Primary Care. Qual Prim Care. 2008;16:351-62

68. Krum H, Tonkin AM, Currie R, Djundjek R, Johnston Cl. Chronic heart failure in Australian general practice: The Cardiac Awareness Survey and Evaluation (CASE) Study. MJA. 2001;174:439-44.

\section{Submit your next manuscript to BioMed Central and we will help you at every step:}

- We accept pre-submission inquiries

- Our selector tool helps you to find the most relevant journal

- We provide round the clock customer support

- Convenient online submission

- Thorough peer review

- Inclusion in PubMed and all major indexing services

- Maximum visibility for your research

Submit your manuscript at www.biomedcentral.com/submit
( Biomed Central 